\title{
Required area of lymph node sampling during segmentectomy for clinical stage IA non-small cell lung cancer
}

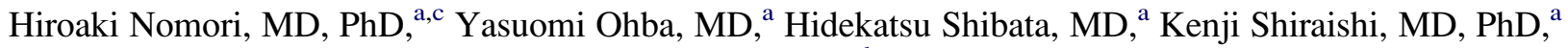 \\ Takeshi Mori, $\mathrm{MD}, \mathrm{PhD},{ }^{\mathrm{a}}$ and Shinya Shiraishi, $\mathrm{MD}, \mathrm{PhD}^{\mathrm{b}}$
}

Objective: To investigate the required area of lymph node sampling during segmentectomy, especially for segmental nodes at the nonresected segments, we examined the distribution of sentinel nodes in patients with nonsmall cell lung cancer who underwent segmentectomy.

\begin{abstract}
Methods: Ninety-four patients with clinical T1 N0 M0 non-small cell lung cancer were treated by using segmentectomy and dissection of lymph nodes with sentinel node identification using ${ }^{99 \mathrm{~m}} \mathrm{Tc}$-phytate. Anatomic locations of the segments were classified as either anterior or posterior, and correlations of anatomic location with the distribution of sentinel nodes at the segmental nodes were then examined.
\end{abstract}

Results: Of the 94 patients, segmental nodes at both the resected and nonresected segments could be dissected in 42 patients. Segmental sentinel nodes were found at the resected segments in 27 (64\%) of these 42 patients, a frequency that was significantly higher than that $(12 / 42[29 \%])$ seen at the nonresected segments $(P=.001)$. Seven $(47 \%)$ of the 15 patients with tumors in the anteriorly located segments had segmental sentinel nodes at the nonresected segments, a frequency that was significantly higher than that $(4 / 24[17 \%])$ seen in patients with tumors in the posteriorly located segments $(P=.04)$.

Conclusion: The lymphatic flow from the anteriorly located segment can frequently go directly to the segmental lymph nodes of the posteriorly located segment, probably because the lobar bronchi locate at the posterior side in the thorax. Therefore segmental lymph nodes should be dissected at both the resected and nonresected segments during segmentectomy, especially for tumors in the anteriorly located segment. (J Thorac Cardiovasc Surg 2010;139:38-42)

Earn CME credits at

http://cme.ctsnetjournals.org

In 1995, the Lung Cancer Study Group reported the results of a prospective randomized control trial of limited resection versus lobectomy for clinical T1 N0 M0 non-small cell lung cancer (NSCLC) and concluded that the former was inferior to the latter regarding local recurrence and survival. ${ }^{1}$ Local recurrences after segmentectomy are known to be caused by the following factors: (1) insufficient surgical margin, (2) missing intrapulmonary metastasis within the same lobe, and (3) missing lymph node metastasis at the hilum, mediastinum, or both. To prevent the last factor, all segmental-lobar-hilar-medias-

\footnotetext{
From the Departments of Thoracic Surgery ${ }^{\mathrm{a}}$ and Diagnostic Imaging, ${ }^{\mathrm{b}}$ Graduate School of Medical Sciences, Kumamoto University, Kumamoto, Japan; and the Division of General Thoracic Surgery, Department of Surgery, School of Medicine, Keio University, ${ }^{\mathrm{c}}$ Tokyo, Japan.

Supported in part by a Grant-in-Aid from the Ministry of Health, Labor, and Welfare of Japan.

Received for publication Jan 24, 2009; revisions received March 11, 2009; accepted for publication April 1, 2009; available ahead print June 18, 2009.

Address for reprints: Hiroaki Nomori, MD, PhD, Division of General Thoracic Surgery, Department of Surgery, School of Medicine, Keio University, 35 Shinanomachi, Shinjuku-ku, 160-8582, Tokyo, Japan (E-mail: hnomori@qk9.so-net.ne.jp). $0022-5223 / \$ 36.00$

Copyright (c) 2010 by The American Association for Thoracic Surgery doi:10.1016/j.jtcvs.2009.04.003
}

tinal lymph node stations should be submitted for intraoperative frozen section examinations to confirm the intraoperative $\mathrm{N}$ staging to be $\mathrm{NO} .^{2-6}$ However, it has not yet been clarified whether segmental lymph nodes at the nonresected segments should be dissected during segmentectomy.

Since April 2005, we have identified the sentinel node (SN) for intraoperative $\mathrm{N}$ staging during segmentectomy by using radioisotopes to target the lymph nodes submitted for intraoperative frozen section. ${ }^{7}$ During segmentectomy, we have endeavored to dissect segmental lymph nodes at not only the resected segment but also the nonresected segment. In the present study, to investigate the required area of lymph node sampling during segmentectomy, we examined the pathologic results and the distribution of SNs, especially at the segmental nodes of the nonresected segments.

Regarding the radioisotope tracers for $\mathrm{SN}$ identification, we used ${ }^{99 \mathrm{~m}}$ Tc tin colloid from April 2005 to December 2006 and have used ${ }^{99 \mathrm{~m}} \mathrm{Tc}$ tin colloid since January 2007. ${ }^{8,9}$ The present study examined patients whose SNs were identified by using ${ }^{99 \mathrm{~m}}$ Tc-phytate from January 2007 to December 2008.

\section{MATERIALS AND METHODS Eligibility}

The study protocol using radioisotopes for $\mathrm{SN}$ identification in patients with clinical stage I NSCLC was approved by the Ethics Committee of the Graduate School of Medical Sciences, Kumamoto University, in March 2005. Clinical staging was performed by using body computed tomographic 


\section{Abbreviations and Acronyms \\ NSCLC $=$ non-small cell lung cancer \\ $\mathrm{SN} \quad=$ sentinel node}

scanning, brain magnetic resonance imaging, and positron emission tomography. All patients provided informed consent after fully discussing the risks and benefits with their surgeons. Eligible patients had clinical stage IA peripheral-type NSCLC and were candidates for segmentectomy with systematic lymph node dissection, as reported previously. ${ }^{7}$

\section{Patients}

From January 2007 to December 2008, 147 patients with clinical stage IA NSCLC underwent surgical treatment. Of these, segmentectomy was planned and requested by 128 patients. Of these 128 patients, 99 received $\mathrm{SN}$ identification with ${ }^{99 \mathrm{~m}} \mathrm{Tc}$-phytate, whereas the remaining 29 did not because their tumors showed ground-glass opacity and were usually stage N0 bronchioloalveolar carcinomas. Lymph node nomenclature was based on the original lymph node map for lung cancer (Table 1). ${ }^{10}$ The pathologic stage was based on the TNM classification of the International Union Against Cancer. ${ }^{11}$

\section{Administration of Radioactive Colloid}

Administration of radiotracers was based on a method reported previously. ${ }^{7,8,12,13}$ Approximately 18 hours before surgical intervention, 6 to 8 $\mathrm{mCi}$ of ${ }^{99 \mathrm{~m}} \mathrm{Tc}$-phytate, which had been suspended in a volume of 1 to 1.5 $\mathrm{mL}$, was injected into the peritumoral region. This procedure was carried out in a room of a coregistered single photon emission computed tomography and computed tomographic imaging (SPECT/CT).

\section{SN Criteria}

The radioactivity of the dissected lymph nodes was measured intraoperatively for 10 seconds with a handheld gamma probe (Navigator; Auto Suture Japan, Tokyo, Japan), as reported previously. ${ }^{7-9}$ A node was defined as an SN when the radioactivity count was greater than 10 times the background level (ie, the radioactivity on the rack where SNs were identified). The identified SNs were submitted for intraoperative frozen section.

\section{Operative Procedures}

Under thoracotomy, segmentectomy with SN identification was performed, as reported previously. ${ }^{7}$ After segmentectomy, nodal stations 10 to 13 , including station 13 at the nonresected segments, were dissected with taping of the segmental vessels and bronchi, followed by mediastinal lymph node dissection. SNs were examined by using intraoperative frozen sections, which were serially cut at 2 to $3 \mathrm{~mm}$ in thickness. Further histologic examination of the dissected lymph nodes was performed with formalin-fixed and paraffin-embedded sections with hematoxylin and eosin staining. If the intraoperative frozen section of SNs showed no metastasis, the operative procedure was completed with segmentectomy. If the frozen sections of SNs showed metastasis, the operative procedure was converted to lobectomy.

\section{Classification of the Anatomic Locations of Segments}

The anatomic locations of segments were classified as anterior, posterior, and apical, as shown in Figure 1. The anterior segment of the right upper lobe (right S3), apical anterior segment of the left upper lobe (left S3), lateral and median segments of the middle lobe (right S4 and S5, respectively), superior lingular and inferior lingular segments of the left upper lobe (left S4 and S5, respectively), and anterior segment of the bilateral lower lobes (S8) were classified as anteriorly located segments. The posterior segment of the
TABLE 1. Lymph node nomenclature

\begin{tabular}{lc}
\hline \multicolumn{1}{c}{ N2 node } & N1 node \\
\hline Superior mediastinal & Hilar \\
No. 1. Highest mediastinal & No. 10. Hilar \\
No. 2. Paratracheal & No. 11. Interlobar \\
No. 3. Pretracheal & No. 12. Lobar \\
No. 4. Tracheobronchial & Intrapulmonary \\
Aortic & No. 13. Segmental \\
No. 5. Botallo's & No. 14. Subsegmental \\
No. 6. Para-aortic & \\
Inferior mediastinal & \\
No. 7. Subcarinal & \\
No. 8. Paraesophageal & \\
No. 9. Pulmonary ligament & \\
\hline
\end{tabular}

right upper lobe (right S2), apical posterior segment of the left upper lobe (left $\mathrm{S} 1+2$ ), and apical, lateral, and posterior segments of the lower lobe (S6, S9, and S10, respectively) were classified as posteriorly located segments. The apical segment of the right upper lobe (S1) was classified as the segment at the apical side.

\section{Statistical Analysis}

Differences in identification rates of SNs among lymph node stations were analyzed for statistical significance by using the $\chi^{2}$ test. All values in the text and tables are presented as means \pm standard deviations.

\section{RESULTS}

There were no complications associated with radioisotope injection, such as bleeding or pneumothorax necessitating tube drainage. Of the 99 patients for whom segmentectomy with SN identification was planned, SNs could be identified in 94 (95\%; Table 2). The radioactivity of background counted by the Navigator (Auto Suture Japan) was usually 0 or 1 . The mean radioactivity of $226 \mathrm{SNs}$ in the 94 patients was $204 \pm 712$ count/s (range, 10-5126 count/s). The mean number of SNs identified was $2.4 \pm 1.3$ nodes per patient. Table 3 shows the distribution of SNs in 5 patients with pathologic N1 or N2 disease. SNs in these 5 patients could be identified during the operation and were shown to have metastases by examination of intraoperative frozen sections. Two of the 5 patients (patients 1 and 2) had SNs at station 13 of the resected segments. All 3 patients with tumors in the left upper lobe (patients 3-5) had metastatic SNs at station 5. The operation was converted to a lobectomy for these 5 patients, except for patient 3 because of his age (ie, 81 years).

At the stations of hilum, the SNs were identified at station 10 in $22(23 \%)$ of the 94 patients, at station 11 in $38(40 \%)$ patients, at station 12 in $33(47 \%)$ patients, and at station 13 in $50(53 \%)$ patients. Stations 13 and 12 had SNs more frequently than station $10(P<.001$ and $P=.001$, respectively). The distribution of mediastinal SNs in each lobe is shown in Table 4. The distribution was mostly lobe specific: stations 3 or 4 for tumors in the right upper lobe, station 5 for 

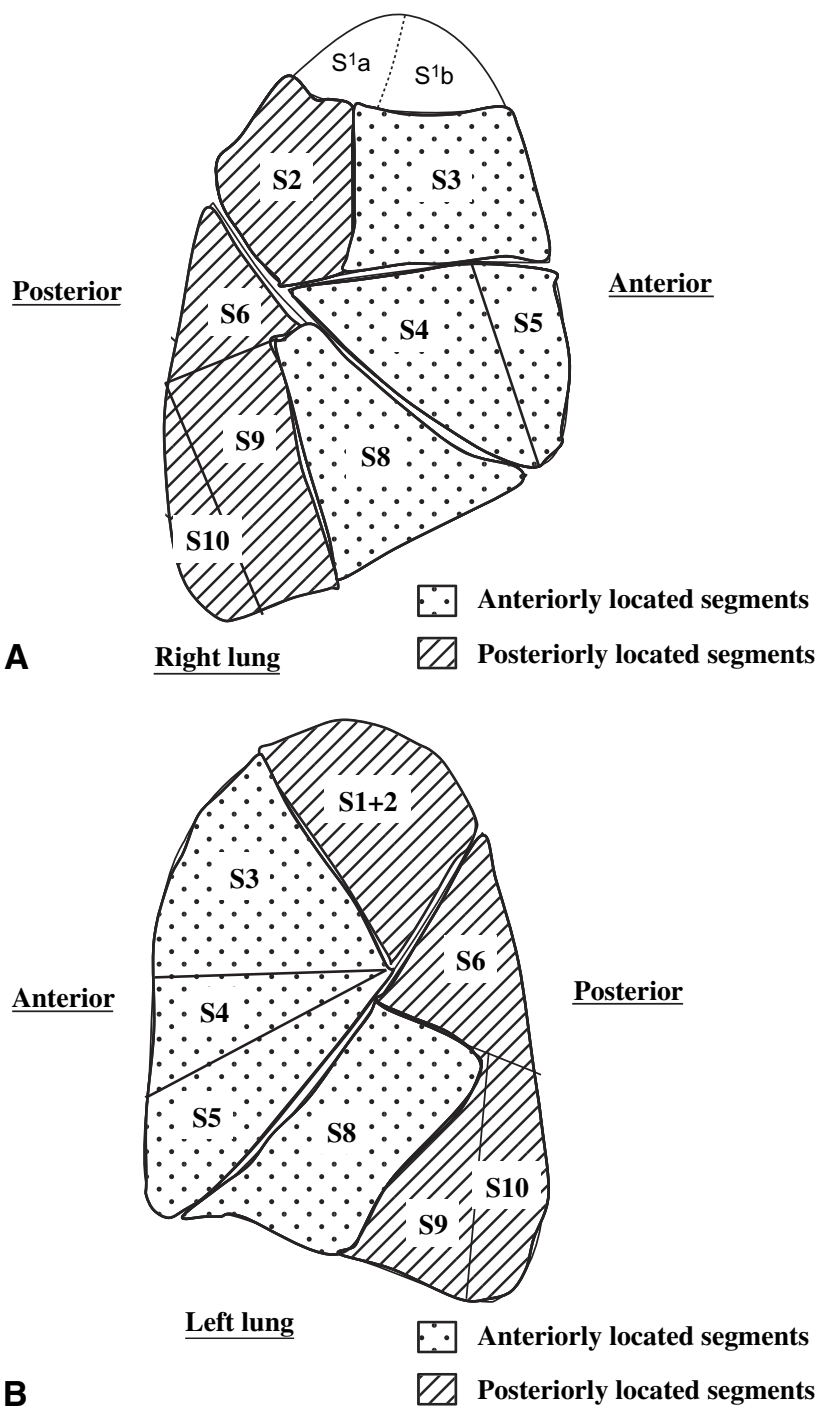

FIGURE 1. Classification of the anatomic locations of segments: A, right lung; B, left lung.

tumors in the left upper lobe, and station 7 for tumors in the bilateral lower lobes.

Station 13 at both the resected and the nonresected segments could be dissected in 42 of the 94 patients. In the other 52 patients, station 13 at either the resected or nonresected segment was not dissectible because it could not be visualized during surgical intervention. Table 5 shows the correlation between the location of station $13 \mathrm{SNs}$ and the locations of the resected segments in the 42 patients. The anteriorly located segments were resected in 15 patients, the posteriorly located segments were resected in 24 patients, and the right $\mathrm{S} 1$ was resected in 3 patient. The station 13 SNs were found only at the resected segments in 18 patients, only at the nonresected segments in 3 patients, at both in 9 patients, and at neither in 12 patients. As a result, the station $13 \mathrm{SNs}$ were found at the resected segments in $27(18+9 ; 64 \%)$ of the 42 patients, whereas
TABLE 2. Characteristics of patients

\begin{tabular}{lc}
\hline Mean age (y) & $64 \pm 10$ \\
Sex & 51 \\
Male & 53 \\
Female & \\
Tumor size (cm) & $1.7 \pm 0.6$ \\
$\quad$ Mean & $0.7-3.0$ \\
Range & \\
Histologic type & 82 \\
Adenocarcinoma & 11 \\
Squamous cell carcinoma & 1 \\
Carcinoid & \\
Tumor location & 27 \\
Right upper lobe & 2 \\
Right middle lobe & 25 \\
Right lower lobe & 30 \\
Left upper lobe & 10 \\
Left lower lobe & \\
Pathologic TNM stage & 88 \\
T1 N0 M0 & 1 \\
T2 N0 M0 & 2 \\
T1 N1 M0 & 3 \\
T1 N2 M0 & 94 \\
Total &
\end{tabular}

they were found at the nonresected segments in $12(3+9 ; 29 \%)$ of the 42 patients. The frequency of station $13 \mathrm{SNs}$ found at the resected segments was significantly higher than that at the nonresected segments $(P=.001)$. Of the 15 patients with tumors in the anteriorly located segments, $7(3+4 ; 47 \%)$, patients had station 13 SNs at the nonresected segments, the percentage of which was significantly higher than that (4 [17\%]) seen in the 24 patients with tumors in the posteriorly located segments $(P=.04)$. Three patients with tumors in the anteriorly located segments had station 13 SNs only at the nonresected segments.

Of the 89 patients who were completed with segmentectomy at stage N0, 2 patients had tumor recurrence at the

TABLE 3. Results of sentinel lymph node identification for patients with pathologic $\mathrm{N} 1$ or $\mathrm{N} 2$ disease

\begin{tabular}{|c|c|c|c|c|c|}
\hline \multirow[b]{2}{*}{$\begin{array}{c}\text { Patient } \\
\text { no. } \\
\end{array}$} & \multicolumn{3}{|c|}{ Tumor } & \multirow[b]{2}{*}{ p-TNM } & \multirow{2}{*}{$\begin{array}{c}\text { Sentinel lymph } \\
\text { node [metastatic } \\
\text { lymph node] }\end{array}$} \\
\hline & Histology & $\begin{array}{l}\text { Size } \\
\text { (cm) }\end{array}$ & Location & & \\
\hline 1 & $\mathrm{AD}$ & & & & \\
\hline 1 & $\mathrm{AD}$ & 3.0 & RUL & T1 N1 M0 & $12,[13]$ \\
\hline 2 & $\mathrm{Sq}$ & 2.7 & RUL & T1 N1 M0 & {$[10], 12,13$} \\
\hline 3 & Ad & 2.0 & LUL & T1 N2 M0 & {$[5]$} \\
\hline 4 & Ad & 2.7 & LUL & T1 N2 M0 & {$[5], 6,[10],[12]$} \\
\hline 5 & $\mathrm{Sq}$ & 2.0 & LUL & T1 N2 M0 & {$[5], 12,13$} \\
\hline
\end{tabular}

Brackets show sentinel nodes with metastasis. $A d$, Adenocarcinoma; $R U L$, right upper lobe; $S q$, squamous cell carcinoma; $L U L$, left upper lobe. 
TABLE 4. Sentinel nodes at the mediastinum in each lobe

\begin{tabular}{lccr}
\hline & \multicolumn{3}{c}{ Sentinel node } \\
\cline { 2 - 4 } Tumor location & Station & No. of patients & $\%$ \\
\hline Right upper lobe & 3 or 4 & $12 / 27$ & 44 \\
Right middle lobe & 7 & $3 / 27$ & 11 \\
& 3 or 4 & $2 / 2$ & 100 \\
Right lower lobe & 7 & $1 / 2$ & 50 \\
Left upper lobe & 7 & $11 / 25$ & 44 \\
& 3 or 4 & $6 / 25$ & 24 \\
Left lower lobe & 5 & $14 / 30$ & 47 \\
& 7 & $2 / 30$ & 7 \\
& 7 & $3 / 10$ & 30 \\
& 5 & $2 / 10$ & 20 \\
& 9 & $1 / 10$ & 10 \\
\hline
\end{tabular}

thoracic wall and supraclavicular lymph node, respectively. The remaining 87 patients are now alive and without recurrence at the median follow-up of 15 months.

\section{DISCUSSION}

The present results highlight the following 3 points. First, although the station 13 SNs were more frequently found at the resected than at the nonresected segments, $29 \%$ of patients still had station $13 \mathrm{SNs}$ at the nonresected segments. Second, tumors in the anteriorly located segments had station $13 \mathrm{SNs}$ at the nonresected segments more frequently than tumors in the posteriorly located segments. Finally, SNs at the mediastinum are mostly lobe specific.

Lymphatic flow at the hilum in patients with NSCLC has not previously been reported. The present results indicate station $13 \mathrm{SNs}$ to be found more frequently at the resected segments than at the nonresected segments, as expected. On the other hand, $29 \%$ of the patients still had station 13 SNs at the nonresected segments. Patients with tumors in the anteriorly located segments had station 13 SNs more frequently at the nonresected segments than those with tumors in the posteriorly located segments. The following factors might explain the distribution of station 13 SNs. The lymphatic flow around station 13 generally goes to the roots of the lobar bronchi, which are located at the posterior side in the thorax. Therefore lymphatic flow from the anteriorly located segment occasionally goes directly to station 13 at the posteriorly located segment without passing through its own station 13. Although we have no experience of metastasis recognized only at station 13 of the nonresected segment during segmentectomy, Yamanaka and colleagues ${ }^{14}$ examined the distribution of metastases at station 13 in 94 patients with small peripheral NSCLC and obtained the following data. Of the 10 patients with metastases at station 13, 6 had these metastases only at the tumor-bearing segments, 1 patient had metastasis only at the non-tumor-bearing segments, and 3 had metastases at both. Taking the results of the present study and those of Yamanaka and colleagues to-
TABLE 5. Correlation between the location of station 13 sentinel nodes and the anatomic location of segments resected

\begin{tabular}{|c|c|c|c|c|}
\hline \multirow{2}{*}{$\begin{array}{l}\text { Location of station } 13 \\
\text { sentinel nodes }\end{array}$} & \multicolumn{3}{|c|}{$\begin{array}{l}\text { Anatomic location } \\
\text { of segments resected }\end{array}$} & \multirow[b]{2}{*}{ Total } \\
\hline & Anterior & Posterior & Right S1 & \\
\hline Resected segment alone & 4 & 13 & 1 & 18 \\
\hline Nonresected segment alone & 3 & 0 & 0 & 3 \\
\hline Both segments & 4 & 4 & 1 & 9 \\
\hline Neither segment & 4 & 7 & 1 & 12 \\
\hline Total & 15 & 24 & 3 & 42 \\
\hline
\end{tabular}

gether, we advocate that lymph node sampling at station 13 during segmentectomy be conducted not only at the resected segments but also at the nonresected segments, especially for tumors located in the anteriorly located segments.

Skip metastasis to the mediastinal lymph nodes has been reported to occur in $20 \%$ to $40 \%$ of patients with NSCLC ${ }^{15,16}$ because of some lymphatic flow going directly to the mediastinum rather than to the hilum. ${ }^{17} \mathrm{We}$ found that the mediastinal SNs were mostly lobe specific (ie, upper mediastinal lymph nodes in tumors of the upper lobe and lower mediastinal lymph nodes in those of the lower lobe), as reported by other authors. ${ }^{15,16,18}$ Two of our 3 patients with tumors in the left upper lobe showed skip metastasis at station 5, which has been reported to be almost N1 station for tumors in that lobe. ${ }^{15,16,18}$ The results of the present study and the previous reports show that lymph node sampling during segmentectomy should be conducted not only at the hilum but also at lobe-specific mediastinal lymph nodes.

Although our data could not evaluate the prognostic significance of segmentectomy with complete lymph node dissection because of a short follow-up period, we could show the required area of lymph node sampling during segmentectomy in patients with clinical stage IA NSCLC. To prevent the local recurrence from lymph nodes after segmentectomy, we recommend the complete dissection of lymph nodes at the hilum, including those of station 13 at both the resected and nonresected segments, especially for tumors in the anteriorly located segments.

\section{References}

1. Ginsberg RH, Rubinstein LV. Randomized trial of lobectomy versus limited resection for T1N0 non-small cell lung cancer. Lung Cancer Study Group. Ann Thorac Surg. 1995;60:615-23.

2. Tsubota N, Ayabe K, Doi O, et al. Ongoing prospective study of segmentectomy for small lung tumors. Ann Thorac Surg. 1998;66:1787-90.

3. Okada M, Yoshikawa K, Hatta T, Tsubota N. Is segmentectomy with lymph node assessment an alternative to lobectomy for non-small cell lung cancer of $2 \mathrm{~cm}$ or smaller? Ann Thorac Surg. 2001;71:956-61.

4. Yoshikawa K, Tsubota N, Kodama K, et al. Prospective study of extended segmentectomy for small lung tumors: the final report. Ann Thorac Surg. 2002;73: 1055-9.

5. Kodama K, Doi O, Higashiyama M, Yokouchi H. Intentional limited resection for selected patients with T1N0M0 non-small cell lung cancer. J Thorac Cardiovasc Surg. 1997;114:347-53. 
6. Okada M, Koike T, Higashiyama M, Yamato Y, Kodama K, Tsubota N. Radical sublobar resection for small-sized non-small cell lung cancer: a multicenter study. J Thorac Cardiovasc Surg. 2006;132:769-75.

7. Nomori H, Ikeda K, Mori T, et al. Sentinel node navigation segmentectomy for cT1N0M0 non-small cell lung cancer. J Thorac Cardiovasc Surg. 2007;133:780-5.

8. Nomori H, Horio H, Naruke T, Orikasa H, Yamazaki K, Suemasu K. Use of technetium-99m tin colloid for sentinel lymph node identification in non-small cell lung cancer. $J$ Thorac Cardiovasc Surg. 2002;124:486-92.

9. Nomori H, Ohba Y, Yoshimoto K, et al. Difference of sentinel lymph node identification between tin colloid and phytate in patients with non-small cell lung cancer. Ann Thorac Surg. 2009;87:906-10.

10. Naruke T, Suemasu K, Ishikawa S. Lymph node mapping and curability at various levels of metastasis in resected lung cancer. J Thorac Cardiovasc Surg. 1978;76: $832-9$.

11. Sobin LH, Wittekind Ch, eds. (UICC) TNM classification of malignant tumors. 6th ed. New York: Wiley; 2002. p.99-103.

12. Nomori H, Watanabe K, Ohtsuka T, Naruke T, Suemasu K. In vivo identification of sentinel nodes for clinical stage I non-small cell lung cancer for abbreviation of mediastinal lymph node dissection. Lung Cancer. 2004;46:49-55.
13. Nomori H, Ikeda K, Mori T, et al. Sentinel node identification in clinical stage Ia non-small cell lung cancer by a combined single photon emission computed tomography/computed tomography system. J Thorac Cardiovasc Surg. 2007;134:182-7.

14. Yamanaka A, Hirai T, Fujimoto T, Ohtake Y, Konishi F. Analyses of segmental lymph node metastases and intrapulmonary metastases of small lung cancer. Ann Thorac Surg. 2000;70:1624-8.

15. Naruke T, Tsuchiya R, Kondo H, Nakayama H, Asamura H. Lymph node sampling in lung cancer: how should it be done? Eur J Cardiothorac Surg. 1999; 16(suppl):S17-24

16. Okada M, Tsubota N, Yoshimura M, Miyamoto Y, Matsuoka H. Prognosis of completely resected $\mathrm{pN} 2$ non-small cell lung carcinomas: what is the significant node that affects survival? J Thorac Cardiovasc Surg. 1999;118:270-5.

17. Riquet M, Hidden G, Debesse B. Direct lymphatic drainage of lung segments to the mediastinal nodes. J Thorac Cardiovasc Surg. 1989;97: 623-32.

18. Asamura H, Nakayama H, Kondo H, Tsuchiya R, Naruke T. Lobe-specific extent of systemic lymph node dissection for non-small cell lung carcinomas according to a retrospective study of metastases and prognosis. J Thorac Cardiovasc Surg. 1999;117:1102-11. 